Case study

\title{
The Giotto's workshop in the XXI century: looking inside the "God the Father with Angels" gable
}

\author{
Marco Gargano ${ }^{a}$, Anna Galli ${ }^{b, c, *}$, Letizia Bonizzoni ${ }^{a}$, Roberto Alberti ${ }^{\mathrm{d}}$, Nicola Aresi ${ }^{\mathrm{d}}$, \\ Michele Caccia ${ }^{\mathrm{b}, \mathrm{c}}$, Isabella Castiglioni ${ }^{\mathrm{b}}$, Matteo Interlenghi ${ }^{\mathrm{b}}$, Christian Salvatore ${ }^{\mathrm{b}}$, \\ Nicola Ludwig ${ }^{\mathrm{a}}$, Marco Martini ${ }^{\mathrm{c}}$ \\ a Dipartimento di Fisica, Università degli Studi di Milano, via Celoria 16, 20133 Milano, Italy \\ ${ }^{\mathrm{b}}$ CNR-IBFM, via F.lli Cervi 93, 20090 Segrate (MI), Italy \\ c Dipartimento di Scienza dei Materiali, Università degli Studi di Milano-Bicocca, via R. Cozzi 55, 20125 Milano (IT) and INFN, Sezione Milano-Bicocca, Italy \\ ${ }^{\mathrm{d}}$ XGLab s.r.l. via Conte Rosso 23, 20134 Milano, Italy
}

\section{A R T I C L E I N F O}

\section{Article history:}

Received 19 March 2018

Accepted 26 September 2018

Available online 24 October 2018

\section{Keywords:}

In situ non-invasive analyses

Giotto panel

MA-XRF

FORS

Scanning IR reflectography

Giotto underdrawing

\begin{abstract}
A B S T R A C T
God the Father with Angels (about 1330, tempera on panel) by Giotto is the Gable of the altarpiece of Baroncelli Chapel in the church of Santa Croce in Florence. Very little is known about its history since the separation from the so-called Baroncelli Polyptych. Now at the San Diego Museum of Art, the Gable had never been studied by means of scientific methods before our team took the opportunity to during the exhibition "Giotto, l'Italia", held in Milan. Exploiting the integration of different knowledge, technologies and resources of our team, we were able to provide data for understanding the organizational model of Giotto's workshop performing non-invasive analyses with portable instruments during closing hours of exhibition (four diagnostic campaigns, six hours of work/campaign, no interruption of the exhibition). The achieved results confirm the painting technique based on different layers of pigments, a technique already used by Giotto. Combining the effectiveness of scanning MA-XRF with the responsive of IR reflectography and IR false colour, we moved step by step toward the discovery of Giotto's palette for the flesh tones in God the Father with Angels. FORS and XRF single point analyses were performed on some selected areas too. The IR reflectography results support the hypothesis of a detailed underdrawing with both thin and flat brushstrokes. By applying image-processing algorithms to the collected reflectograms, we obtained quantitative objective measures supporting the hypothesis that a guide could have been used in the realization of human figures; this means the use of sketches for the face of "God the Father" and for the faces of angels.
\end{abstract}

(C) 2018 Published by Elsevier Masson SAS.

\section{Introduction}

Giotto (1266-1337), an Italian painter and architect, was born in Florence and is considered the first of many great artists who contributed to the beginning of the Italian Renaissance. The exhibition Giotto, l'Italia. Da Assisi a Milano (from Assisi to Milan) at the Palazzo Reale in Milan hosted a sequence of masterpieces, for the first time together in a single exhibition. Remarkable presence has been the Baroncelli altarpiece, from the church of Santa Croce in Florence, which has been reunited in the exhibition with its Gable [1]. God the Father with Angels (about 1330), an egg tempera and gold on panel, was in fact separated from the Baroncelli polyp-

\footnotetext{
* Corresponding author at: CNR-IBFM, via F.lli Cervi 93, 20090 Segrate (MI), Italy. E-mail addresses: anna.galli@unimib.it (A. Galli), info@xglab.it (R. Alberti).
}

tych at the end of the XV century [2] and is now held in the San Diego Museum of Art, California, United States. While the polyptych has been studied through analytical techniques during the recent restoration, the Gable had never been studied before.

In general, such acclaimed exhibitions could potentially be a perfect opportunity for analytical campaigns; unfortunately, due to the necessity of a strict organization, setting timetables and immoveable position of the masterpieces, they are usually not enough exploited. For this work, we fine-tuned a protocol that allowed to get a depict of pigments, conservation state and history of the painting, during the only half-day closing of the exhibition, without moving the panel from its displaying position at $2 \mathrm{~m}$ height from the ground.

All the analyses presented in this paper - macro X-Ray Fluorescence spectrometer (MA-XRF), Fiber Optics Reflectance Spectroscopy (FORS), Infrared Reflectography (IRR) and Infrared 
False Color (IRFC) - have been performed with portable and fast assembling instrumentation and were chosen for being totally noninvasive, non-destructive and, excluding FORS, contactless. Also post processing of data were finalized with fast, automatic and reliable handling, so that results could be presented while the exhibition was still going on, giving added value to the exposition itself and immediate return to the users. In this perspective, all imaging methods offer undeniable advantages. In particular, Infrared reflectography can be used to visualize the underdrawings of ancient paintings, as most pictorial layers are transparent to near-infrared radiation between $0.8 \mu \mathrm{m}$ and $2.5 \mu \mathrm{m}$. Conversely, carbon-based materials used for underdrawings are usually a good near infrared (NIR) absorber [3,4,5]. Getting information from the underlying layers also allows visualizing composition changes introduced either by the artist himself or during further interventions. IRFC image can be obtained combining the green and red channels of the RGB colour image with the IR image. The result is a false colour image that allows the immediate identification of pigments with different chemical composition but characterised by similar colours. Areas with different colours in the IRFC image can be therefore representative of the different pigments used in artwork [6,7]. This kind of images individuates different pigments in areas of the same colour, highlighting previously unknown restoration areas [8]. Overlapping this result with chemical information allows then to unambiguously identify each pigment. The MAXRF scanning spectrometer joins imaging techniques and chemical mapping: it allows a non-destructive and non-invasive elemental analysis also in air making the study of the stratigraphic distribution of elements feasible for cultural heritage objects. For both IRR and XRF, the scanning systems allow extending the analysed area increasing the spatial resolution without limits in term of portability and shape or position of the sample $[9,10,11]$. For selected areas, XRF local spectra were compared with local FORS spectra, acquired precisely on the same spot, integrating chemical and optical measurements and overcoming the specific limits of the two techniques. In fact, XRF includes spectral coverage for most elements present in the pigments $(Z>13$ in air atmosphere), but needs an accurate data handling to get correct information on stratigraphic layer sequence when performed on single measuring points. FORS is based on selective absorption of materials due to molecular electronic transitions: the obtained reflectance spectrum exhibits unique characteristics to different pigments. The identification of pigments in the most external layer by reflectance spectra allows inferring the composition of the underlying layers when $\mathrm{XRF}$ analysis is made in the same area. The additional importance of FORS is related to the possibility of detecting with great accuracy pigments made with light elements, which XRF cannot identify $[12,13,14]$.

In general, the methods and the materials used to execute a panel painting are common to most of medieval Italian masterpieces: the wooden panel is prepared with gesso grounds, painted in egg tempera and gold. Yet, when examined in detail, they reveal variations in materials and considerable differences in the application techniques. The leading painter in Florence at the beginning of the fourteenth century was Giotto, assisted in its workshop by apprentices such as Taddeo Gaddi and possibly Bernardo Daddi.

Giotto's contemporaries, such as Dante Alighieri, already recognised that he changed the course of painting. Cennino Cennini [15] stated that Giotto changed the language of painting from Greek to Latin, meaning that he forsook the Byzantine iconic style for a more classical, naturalistic style. The laws of perspectives had not yet been formalised, but Giotto was one of the first painters to take into account the viewpoint of the spectator in designing coherent compositions intended to be seen from a particular angle, and with a correct light direction.
Giotto in his panel paintings (Polyptychs, Crucifixes. ..) used pictorial techniques similar to those described for painting on wood in 1400 by Cennino Cennini, which have been observed in works by his contempories [15]. The artist used an inky wash to lay in the shaded parts of the flesh and the mantle [16,17,18,19,20,21]. Then, working in egg tempera, he applied overlapping strokes of thin paint to model the forms. For the most part the pigments he used part of the typical early fourteenth century palette, even if in a case he applied unexpected colorants derived from a green-blue mineral, mixite, and a copper-bismuth arsenate [22]. However, if the materials were usual, he gave authentic colour to the hair and faces, eschewing the accepted standard of dull, nondescript details and all emphasis on the work's sanctity. He also incorporated bold greens, yellows, oranges and reds to communicate emotion, quite unusual at the time, Giotto painted the world as it is colourfully.

To deeper understand the construction work of the gable, we applied the IR reflectography image post processing. This approach was aimed to the extraction of objective and quantitative image features of underdrawing. The purpose was to answer an open question: are the drawings in the Gable comparable with other drawings and then compatible with an organization example of work, which included the use of models and sketches for a more efficient realization? These models (Patrones) are particular shaped figures made of transparent wax paper used to guide the artist in the drawing of repetitive and modular elements such as figures or architectural elements [23]. They are more common in the fresco paintings, but their use could be applicable to other kind of paintings too. As an example, we explored these hypotheses by comparing the IR reflectographies obtained from the Gable with the reflectography published in literature [24].

\section{Research aims}

The ultimate goals of this paper were to reconstruct the pictorial techniques, besides individuating the materials used, and to study the underdrawings of this masterpiece: this information will be of great help for the knowledge of the technique and the role of the workshop in its execution.

\section{Materials and methods}

Due to the unique opportunity to examine the Giotto's Gable "God the Father with Angels" during the exhibition, all the analyses had to be performed in situ in the room where the artwork was displayed. As detailed in the introduction, we exploited only portable instruments, characterised by a fast acquisition and processing time. The entire diagnostic campaign ( 4 techniques as illustrated in the following) has been performed during four almost simultaneous work sessions of 6 hours each without any interruption of the exhibition (half-day closing of the exhibition).

\subsection{Sample description}

"God the Father with Angels" is an egg tempera and gold on poplar panel $(76.2 \times 71.1 \mathrm{~cm})$ attributed to the Florentine artist Giotto Di Bondone (1267-1337). In this depiction, six angels floating in a heavenly state pay tribute to God centred in the painting. This piece was originally a part of a larger altarpiece known as the Baroncelli polyptych commissioned for the Baroncelli Chapel in the church of Santa Croce in Florence (Italy). The pieces were then separated: the main altarpiece remained in Florence and G̈od the Father with Angels" was privately purchased and later gifted to the San Diego Museum of Art where it is currently stored. In the Milan exhibition, it was positioned two metres from the floor, beside the Baroncelli Polyptych to draw the attention of the pub- 


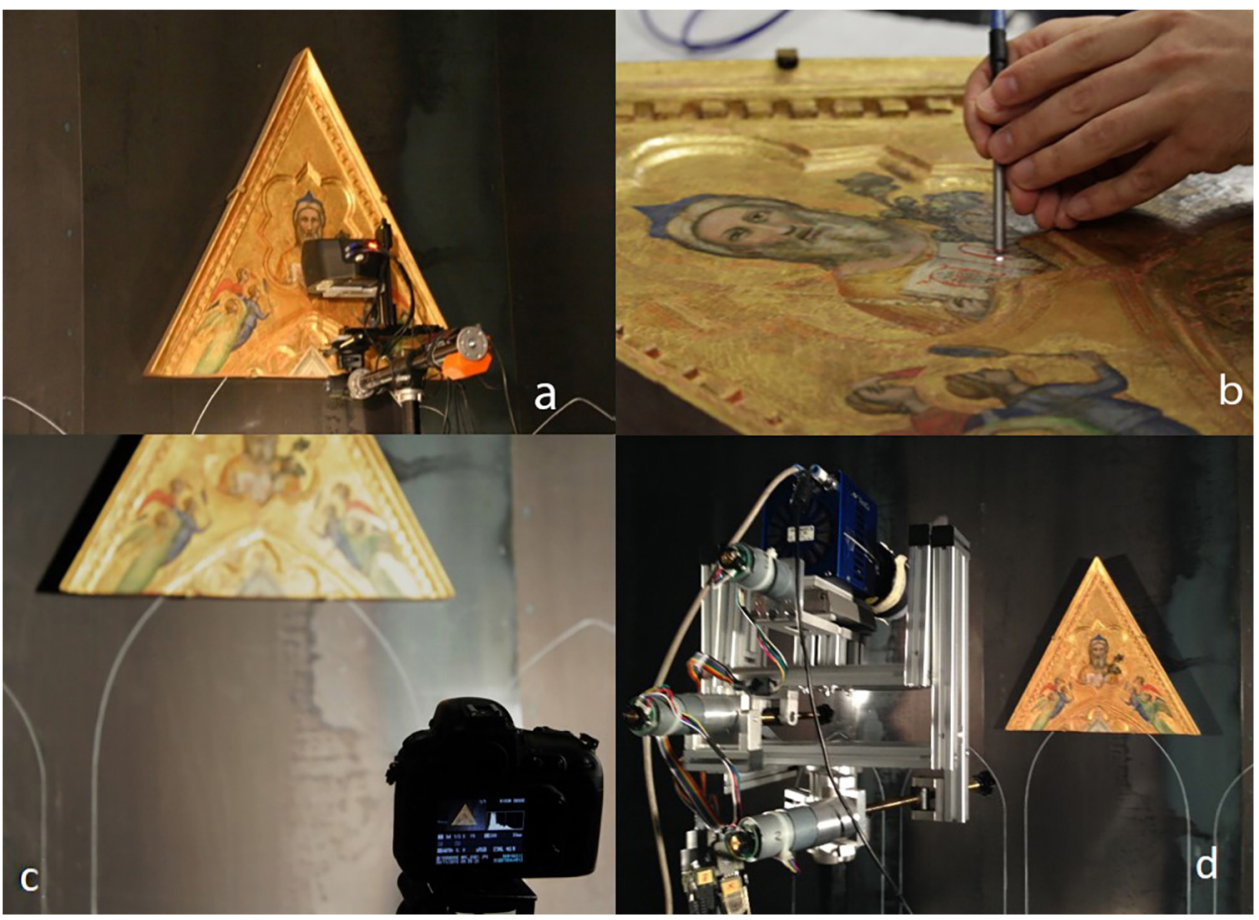

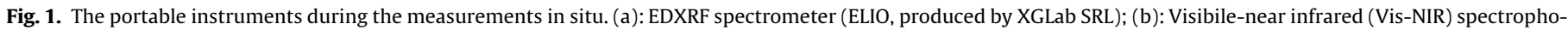
tometer (HR4000, Ocean Optics); (c): DSLR full frame Nikon D800E camera; (d): IR spherical scanning system prototype.

lic to their strong continuity and to the original structure of the polyptych itself.

\subsection{Equipment and settings}

Starting from the consideration that the panel cannot be moved from its exhibition place and that the in situ analyses must be compliant with the exhibition hours, we chose synergic and complementary analytical techniques to get information about the stratigraphic sequence of pictorial material and the underdrawing study. The image processing was simultaneously performed so that the results achieved have been ready for the public to enjoy before the end of the exhibition.

\subsubsection{Pigment analyses}

3.2.1.1. EDXRF. The instrument used in this study is a portable Energy Dispersive XRF (EDXRF) spectrometer (ELIO, produced by XGLab SRL), with elemental mapping capability (MA-XRF scan, Fig. 1a). Elio is based on a large area Silicon Drift Detector (SDD) of $25 \mathrm{~mm}^{2}$ coupled with state-of-art electronics and on a low-power (4 W) transmission X-Ray tube with Rh anode equipped with a pinhole collimator of $1 \mathrm{~mm}$ diameter to create an X-Ray beam on the sample of the order of $1.2 \mathrm{~mm}$ diameter. The instrument is specifically designed to operate in a complete non-contact mode, with a typical distance of $14 \mathrm{~mm}$ between the detection head and the sample. The compact detection head can be installed on an $\mathrm{X}-\mathrm{Y}$ motorized translator stage $(100 \mathrm{~mm} \times 100 \mathrm{~mm}$ total travel $)$ to perform automatic scans and analysis of the selected area or line. All the system is mounted on a standard and light tripod with a grip ball for free 3D positioning of the instrument.

A total amount of 19 single point measurements $(50 \mathrm{kV}, 80 \mu \mathrm{A}$, $120 \mathrm{sec}$ ) have been performed and analysed in order to accurately identify the elemental composition of the pigments (Fig. 2a, b, c). Moreover, mapping measurements have been performed to collect statistical information on the elemental distribution and possible correlation keeping the same settings for the X-ray tube $(50 \mathrm{kV}$ and $80 \mu \mathrm{A}$ ) and an acquisition d-well time of $1 \mathrm{~s}$ for each point. The total XRF map, $60 \times 30$ pixels, $60 \times 30 \mathrm{~mm}^{2}$ with a lateral step of $1 \times 1 \mathrm{~mm}$, has been recorded in about 50 minutes [25] (red rectangle in Fig.2c).

3.2.1.2. FORS. Portable visible-near infrared (Vis-NIR) spectrophotometer (HR4000, Ocean Optics) was used on the same single points of EDXRF analysis (Fig. 1b) [26]. The spectrophotometer was connected to a tungsten halogen light source (D65, HL2000, Ocean Optics): radiation was transmitted through a quartz fibre optics bundle 1.5-meter-long (Ocean Optics), composed by six fibres to collect reflected light around the single central illuminating fibre using $45^{\circ} \times: 45^{\circ}$ measuring geometry. It was also connected to a laptop and calibrated using white and black reflectance standards (Spectralon ${ }^{\circledR} 99 \%$ and dark trap). Vis-NIR reflectance spectrum from $380 \mathrm{~nm}$ to $1000 \mathrm{~nm}$ was acquired for each sample (spectral resolution of $2.7 \mathrm{~nm}$, Fig. 2a, b, c).

\subsubsection{High resolution imaging techniques}

3.2.2.1. Infrared false colour. The IRFC (Infrared False Colour) imaging analysis have been performed using a DSLR full frame Nikon D800E camera (4912 $\times 7360$ pixel, raw image, X-Rite ColorChecker for white and colour profile calibration) modified to extend its sensibility from UV to NIR (350-1000 nm, Fig. 1c). An interferential long-pass filter $(\lambda>850 \mathrm{~nm})$ was used to cut the visible wavelengths. The resulting images have a spatial resolution of 700 pixel/inch (28 points $/ \mathrm{mm}$ ). The acquisition and the post processing to obtain IRFC images has been performed with the traditional experimental set up and procedures [7].

3.2.2.2. Infrared reflectography. IR reflectography (IRR) has been performed with a portable scanning system prototype based on a spherical scanning system [27]: an InGaAs camera (Xenics Xeva1.7-320, $320 \times 256$ elements, spectral sensitivity: $1000-1700 \mathrm{~nm}$ ) is mounted on a motorized head that allows precise and small movements $\left(0.01^{\circ}\right.$ resolution for the rotations and $0.1 \mathrm{~mm}$ for the linear stage). This system allows to acquire IR images corresponding to a surface up to $1 \mathrm{~m} \times 1 \mathrm{~m}$ with a resolution of 256 pixels per 


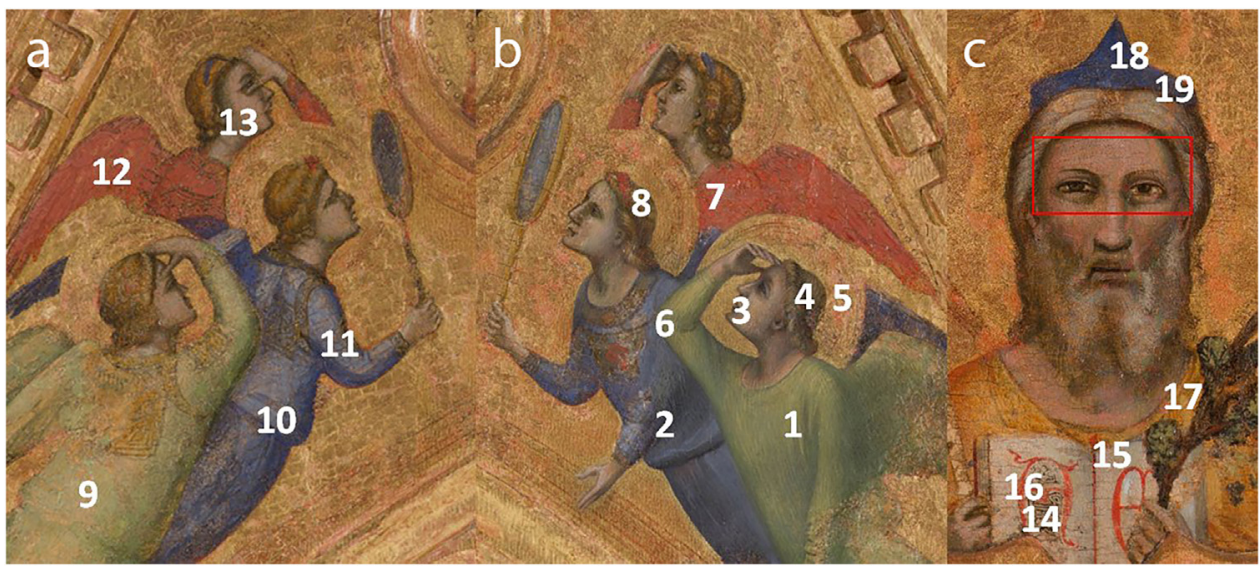

Fig. 2. EDXRF and FORS measurement spots. The red rectangle indicates the analysed area by MA-XRF.

inch (10 points per mm) (Fig. 1d). For the Giotto's panel, 691 images have been stitched to obtain the composition of the whole image.

\subsubsection{Data processing}

3.2.3.1. Mapping of pigment materials. We developed a specific algorithm for the automatic processing of the raw data acquired by the ELIO MA-XRF scanner. The data are stored as a threedimensional dataset in a HDF5 standard compressed format, composed by the spatial coordinates (two-dimension) and a third axis representing the $\mathrm{X}$-ray spectra detected by ELIO. Looking at the whole spectra dataset, we calculated the "Global Spectrum", GS: a spectrum where the intensity (usually plotted against energy) is substituted by the times a meaningful signal has been detected at that energy. This makes the GS a summary of the main X-ray lines in the mapped area where the position of the local maxima reveals the presence of specific emission lines and its abundance [25]. In particular, the MA-XRF measurements were performed in the region around the eyes of God the Father as will be shown in the next sections.

3.2.3.2. Study of the underdrawing. By performing an image segmentation on the IRR images of both God and Angels (segmentation threshold $=0.2$; choice based on intensities of darker brush strokes) and applying a binary mask to the resulting image it has been possible to extract features that can be correlated with the "preparatory" drawings.

As an example, we compared, the segmented image of the God with the IRR image of the face of the blessing Christ of the Ognissanti Cross [28]. A rigid co-registration between the two images was performed for this purpose. In order to compare quantitatively the two images we measured anatomical features of the two faces, namely: the distance between the two pupils, the distance between the two ears, the distance between the hairline and nose bottom and the mouth width. We then compared the ratios among these distances in both images. For the Angels, in order to extract the contour of the faces, we applied a second threshold-based algorithm identifying one isoline of width $=0.5$. To individuate the possible use of sketches for the drawing of the Angels figures, a rigid co-registration of the face contours has been performed and a comparison among the co-registered face contours has been obtained using the Structural Similarity Index (SSI). This value assess the similarity between two images (range $0-1,1=\max$ similarity), based on three image characteristics (i.e. luminance, contrast and structure). In this specific case, the evaluation was based only on the structure differences of the contours [29].

\section{Results and discussion}

\subsection{Pigments and hypothesis of stratigraphy}

As we have mentioned in the introduction, the information on palette used in this panel can be inferred by adopting an experimental non-invasive approach in which the combined use of EDXRF and FORS analyses gives exhaustive answers (see Table 1). The traditional method of stratigraphic analysis based on optical observation of the cross sections was therefore overcome along with its requested microsampling [12,13,14].

Natural ultramarine and cobalt blue in the restored areas were found for blue details. Chromium oxide green was found in the investigated green areas, proving that none of them still shows the original pigment. Brown was mainly obtained through a mixture of ochre and vermillion; red ochre and vermillion were also used for red details; yellow ochre and lead based yellow mixtures for yellow areas, and lead white for white areas. As an example of the joint participation of the techniques applied to the panel, the highresolution image in the visible wavelength range (resolution of 700 ppi) of measurement point 11 is reported in Fig. 3a. The false colour image (Fig. 3b), with the typical red response due to the presence of ultramarine (the green areas in this image correspond to some modern restorations), confirms the point analyses performed on the same area (the empty circle in Fig. 3a). In fact, the FORS spectrum shows the typical trend of ultramarine mixed to lead white (the relative reflectance grows up after $700 \mathrm{~nm}$, see Fig. 3c) and the EDXRF analysis detects, in addition to trace elements as $\mathrm{S}, \mathrm{K}, \mathrm{Ca}, \mathrm{Sr}$, Fe, Ti, Mn, the presence of $\mathrm{Si}$ and $\mathrm{Pb}$ (Fig. 3d).

Interesting is the black colour present in the book: EDXRF analysis and FORS do not show any characteristic elements or trend, being iron and lead present in all the analysed areas. IR reflectograms help in the interpretation of single point data: the sign of the writing is present in the images acquired with the full frame DSLR Nikon D800E (Silicon detector, Fig. 4a), but the same sign is very weak in the images acquired with the IR scanner (InGaAs detector, Fig. 4b) on the same part of the painting. This is probably due to the presence of a mixture of charcoal black (detectable by both the detectors) with black iron-gall ink that becomes transparent after about $1000 \mathrm{~nm}$ [30].

If the original pigments identified did not come as a surprise, what sounds more interesting is the structure of the preparation layers: processing of $1800 \mathrm{MA}-\mathrm{XRF}$ spectra acquired from the God face, we were able to obtain a distribution of the most abundant elements. Beside this spatial information, an algorithm that automatically identifies the transition bands from the distribution of the peaks location has been studied [25]; it organizes the spectra as a 

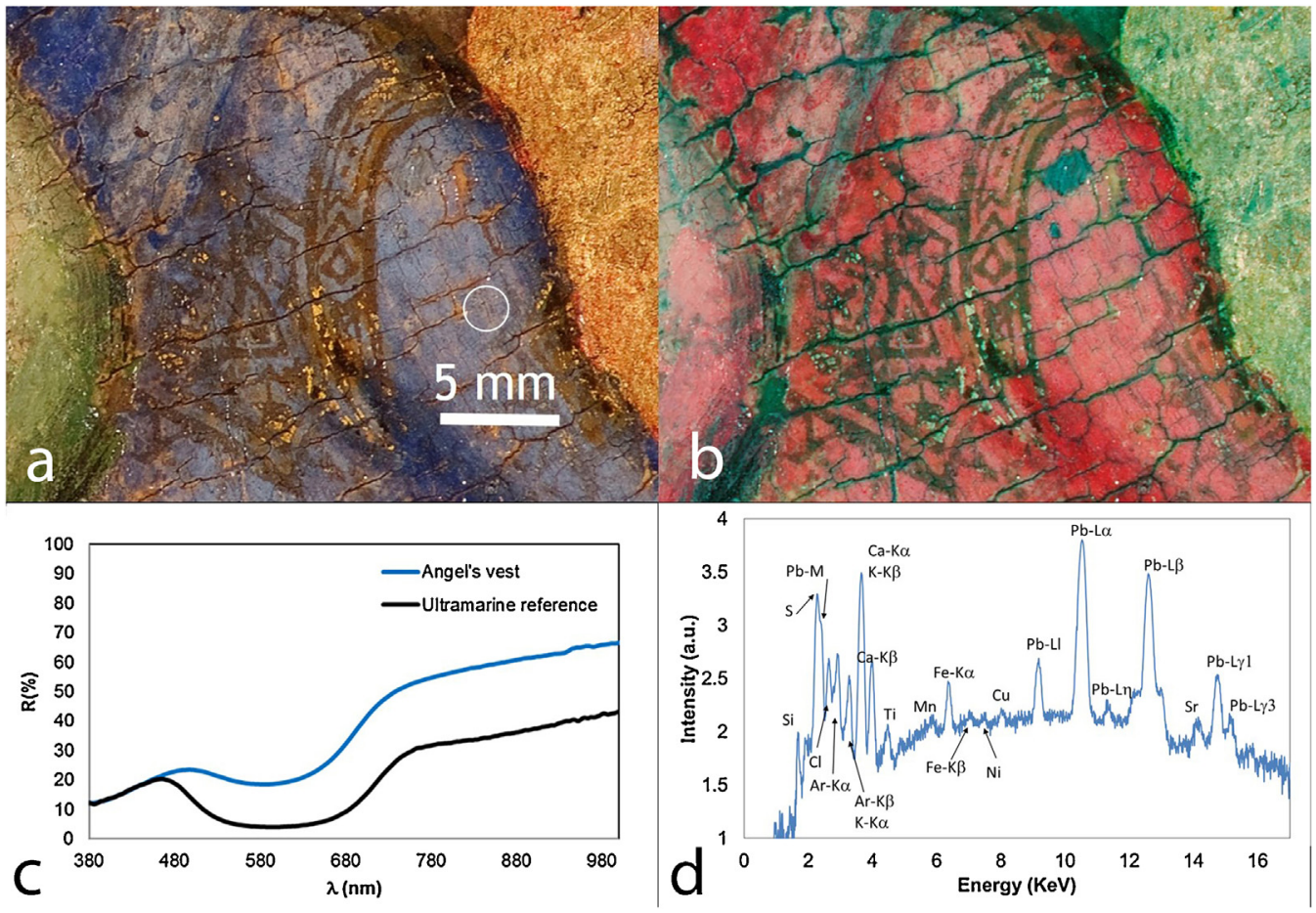

Fig. 3. Angel on the left (a): high-resolution image in the visible wavelength range (resolution of $700 \mathrm{ppi}$ ); (b): false colour image; (c): FORS spectrum performed on the spot 11 labelled with the white circle in Fig. 3a; a red-shift of the maxima of the spectra in correspondence of the Angel's vest, with respect of the reference is very common and caused by the yellowing of the varnish; d: EDXRF spectrum acquired from the spot 11 labelled with the white circle, same as FORS, in Fig. 3a.
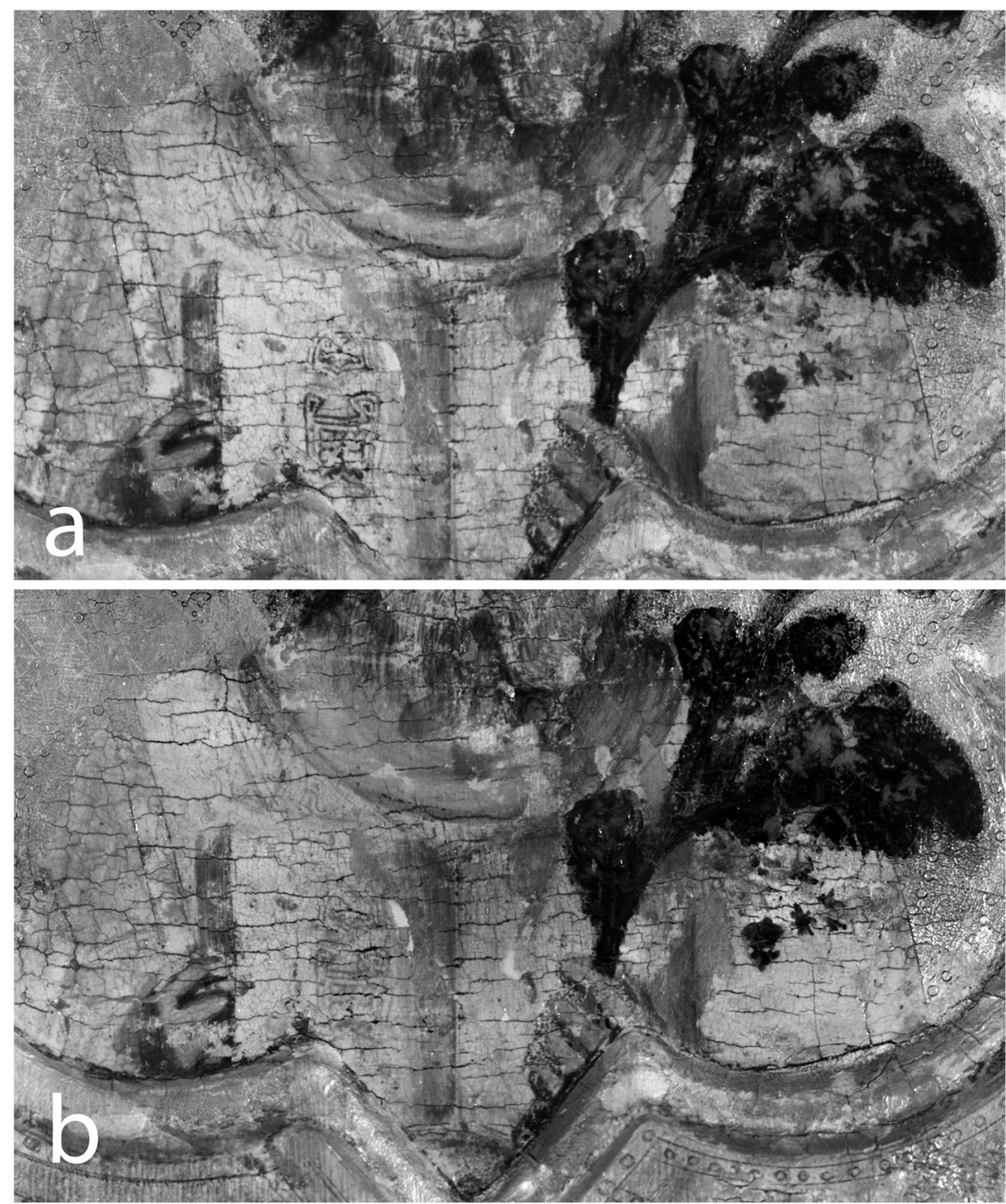

Fig. 4. Comparison between IR reflectograms acquired with the full frame DSLR Nikon D800E camera (a: silicon detector) and the IR scanner (b: InGaAs detector). 
Table 1

Pigment's palette identified in the Gable. Measurement points are reported in Fig. 2a, b, c.

\begin{tabular}{|c|c|c|}
\hline Colour & Measurement points & Pigments \\
\hline Blue/light_Blue & 11,18 & Natural ultramarine $\mathrm{Na}_{8-10} \mathrm{Al}_{6} \mathrm{Si}_{6} \mathrm{O}_{24} \mathrm{~S}_{2-4}$ ) (in some cases with lead white $\mathrm{PbSO}_{4} \cdot \mathrm{PbO}$ ) \\
\hline Brown & 4,8 & Ochre $\left(\mathrm{Fe}_{2} \mathrm{O}_{3} \cdot \mathrm{H}_{2} \mathrm{O}+\mathrm{MnO}_{2}\right.$, clay) and vermillion ( $\left.\mathrm{HgS}\right)$ in mixture over a lead white ground \\
\hline \multirow[t]{2}{*}{ Red } & $12,13,15$ & Vermillion (in some cases with white lead) \\
\hline & 7,12 & Vermillion and gold \\
\hline Yellow & 17 & Ochre \\
\hline Flesh tones & 3,13 & Vermillion and white led \\
\hline White & 15 & Lead white \\
\hline Black & 14 & Charcoal black mixed with iron-gall black ink \\
\hline Gold & 5 & Vermillion on gold \\
\hline \multicolumn{3}{|l|}{ Restoration areas } \\
\hline Colour & Measurement points & Pigments \\
\hline Blue & $2,10,19$ & Cobalt blue $\left(\mathrm{CoO} \cdot \mathrm{Al}_{2} \mathrm{O}_{3}\right)$ over lead white \\
\hline Green & $1,6,9$ & Chromium oxide green $\left(\mathrm{Cr}_{2} \mathrm{O}_{3}\right)$ in some cases with lead/tin based yellow \\
\hline
\end{tabular}

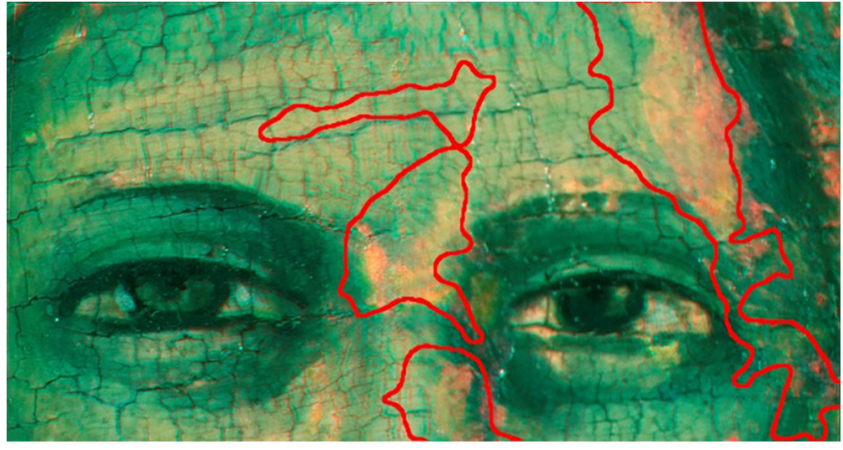

Fig. 5. IRFC image of the portion of the gable mapped by XRF. Orange-red regions identify the most $\mathrm{Ti}-\mathrm{Cr}$ reach areas; the ROIs result from the application of the $\mathrm{Li}$ iterative threshold method described in [24].

3D matrix and integrating into energy it computes the band images. In the quoted paper, the band images were arranged as vectors and the normalized cross-correlation functions (nCCF) were computed to study the matrix of the nCCFs' 0-lag elements.

Respect to the multivariate analyses (as ICA, NMF. . .), the global spectrum GS approach is not aimed to reduce the variables to the independent ones. It selects the energy location of all the possible spatial distribution looking at every spectrum in terms of local maxima (i.e. single emission series). The result is a set of new variables constituted by all the significant spatial series distributions; they are statistically dependent and by analysing their degree of mutual correlation, it is possible to infer conclusion about the present pigments and their organization.

The results obtained showed that two groups of band images are closely cross-correlated (the $\mathrm{M}$ series and $\mathrm{L}$ series of $\mathrm{Hg}$ - $\mathrm{Pb}$ and the K series of $\mathrm{Ca}-\mathrm{Fe}-\mathrm{Cr}-\mathrm{Sr}$ ) but anti-correlated each other [25]. The detection of the $\mathrm{M}$ lines of $\mathrm{Hg}$ and $\mathrm{Pb}$ has been interpreted as a superficial layer of vermilion and white lead superimposed on a Verdaccio layer. Verdaccio is a pigment based on a green earth typical used in the Giotto's period. It is interesting to note that Giotto had already adopted this technique for S. Giovanni flesh tones in the Santa Maria Novella Cross [31] as an alternative to the monolayer mixture of vermillion, lead white and Verdaccio used in the Christ flesh in the Ognissanti Cross [24]. In ref. 25, the correlation between $\mathrm{Cr}$ and $\mathrm{Ti}$ has been ascribed to the modern restoration already quoted. The presence of a restoration area is also confirmed by IR false colour image (orange/red coloured regions in Fig. 5). To better compare the elemental maps of $\mathrm{Cr}$ and $\mathrm{Ti}$ (already published in [25]) with the IRFC one, the mean of the normalized Ti and Cr single elemental maps has been first transformed by a re-scale transformation and a rigid roto-translation and then segmented applying the Li iteratively threshold method [32] in ImageJ/Fiji software
[33]. Briefly, the Li algorithm selects as threshold the grey value which minimizes the cross entropy between the starting image and its thresholder counterpart. The cross entropy is defined as the Kullback-Leibner distance [34], a parametric indicator of the similarity of two distributions of the same nature. Even if the MA-XRF is limited by ELIO lateral step capability (i.e. 1 point/mm while IRFC images rely on a resolution of 28 points $/ \mathrm{mm}$ the ROIs (Region of Interest) there is a quite good superposition between the distribution thus obtained (red delimited regions) and the areas identified as restorations in the IRFC image (Fig. 5).

The ROIs obtained by the segmentation exclude some areas that IRFC technique individuates as restorations; this mismatch could be due to the different depths probed by the two involved techniques and the different crossed layers. $\mathrm{Cr}$ and $\mathrm{Ti}$ are due to a quite recent restoration work; consequently, they are present in the very superficial layer. The IRFC technique is more sensitive to the surface layers, whereas XRF analysis investigates the surface and the subsurface layers. The areas included by the ROIs could be involved in the filling of some gaps: the modern pigments are prevailing on the original ones and detected by both techniques. Moreover, the excluded areas could be ascribed to modern veils; in this case, the IRFC could efficiently detect the $\mathrm{Cr}$ and $\mathrm{Ti}$ based pigments while EDXRF is not so sensitive.

\subsection{The underdrawing: sketches or not}

Considering the upper part of the face of God the Father we can see a blue hat, painted with ultramarine (Fig. 6a), which became completely transparent in the near infrared (Fig. 6b) except for some darker areas in correspondence of the restorations. This detail, together with other restorations and areas of material loss, is well highlighted in IRFC (Fig. 6c). The reflectography (Fig. 6b) shows the underdrawing, mostly as outline of the head, the hat and for the drawing of the hair. Golden decorations of the hat, as an example, have been applied on a preparatory drawing scheme, which appears dark in the near infrared image. In this area, we see the round spots on the tip of the hat and its central decorations.

It is interesting to note that the IR reflectograms show the typical drawing techniques of Giotto with the use of thin and large brushstrokes with carbon black ink (Fig. 6b). For the God's hair and beard, the lines are thin and marked, while for the Angel's face (Fig. 6e), the master proceeded overlaying large brushstrokes to obtain the desired saturation in the shadows. In the Angel's hair, soft and fluid lines are used. Both the IR and IRFC images (Figs. 6e and $6 f$ ) revealed the geometrical decorations of the Angel's dresses, details now concealed in the visible image (Fig. 6d).

The segmented image of reflectograms of God are shown in Fig. 7a. As an example we compared the segmented image with 


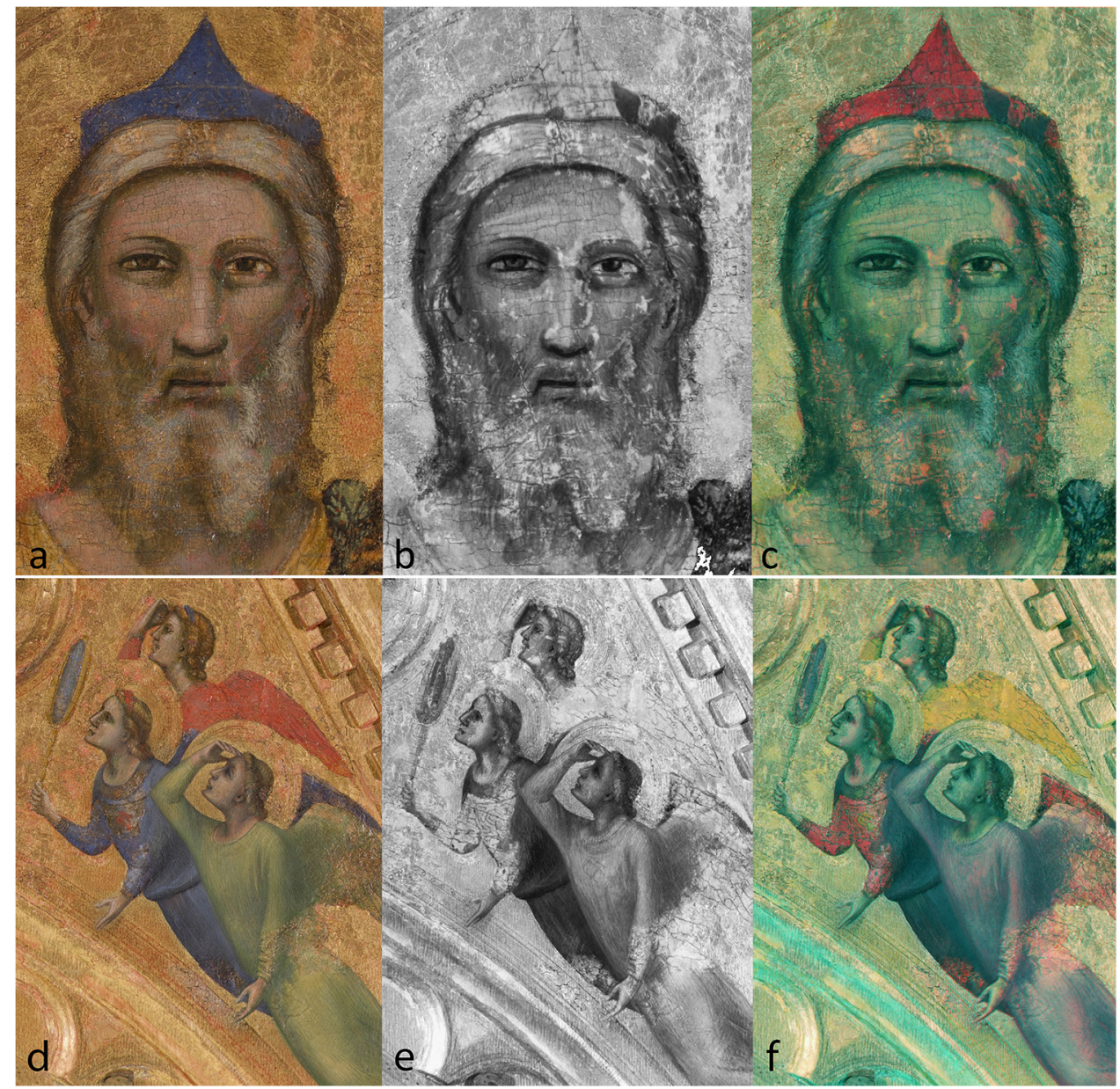

Fig. 6. Visible (a), IR (b) and IRFC (c) images from the God's face. Visible (d), IR (e) and IRFC (f) images of the angels on the right side of the gable.

\section{Table 2}

Anatomical features ratios of both the God Father of the Gable and the Blessing Christ of the Ognissanti Cross (A/A' - pupils distance in God the Father/Blessing Christ, B/B' - ears distance in God the Father/Blessing Christ, $C / C^{\prime}$ - the hairline-nose bottom distance in God the Father/Blessing Christ and D/D' - mouth width in God the Father/Blessing Christ), with the percent differences between corresponding ratios.

\begin{tabular}{lll}
\hline $\begin{array}{l}\text { God Father } \\
\text { anatomical } \\
\text { features ratios }\end{array}$ & $\begin{array}{l}\text { Blessing Christ of the } \\
\text { Ognissanti Cross anatomical } \\
\text { features ratios }\end{array}$ & $\begin{array}{l}\text { Differences } \\
\text { between ratios } \\
(\%)\end{array}$ \\
\hline $\mathrm{A} / \mathrm{B}=0.44$ & $\mathrm{~A}^{\prime} / \mathrm{B}^{\prime}=0.44$ & $0.0 \%$ \\
$\mathrm{~A} / \mathrm{C}=0.55$ & $\mathrm{~A}^{\prime} / \mathrm{C}^{\prime}=0.55$ & $0.0 \%$ \\
$\mathrm{~A} / \mathrm{D}=1.74$ & $\mathrm{~A}^{\prime} / \mathrm{D}^{\prime}=1.61$ & $7.5 \%$ \\
\hline
\end{tabular}

the IR reflectography image of the face of the blessing Christ of the Ognissanti Cross [24] (Fig. 7b). In Fig. 7c the rigid overlapping of the two images is provided, showing the good correspondence between contours of the face, in particular, the hairline, eyes, nose, cheekbones shape and mouth.

Generally speaking, a comparison among anatomical features could be made also using visible portraits, in this particular case the IR reflectography allows to visualize the underdrawing which is the original trace made by the artist before adding pigments. Excluding the visible features from the outlines, we are sure to compare the underdrawing of one particular figure with the underdrawing of other figures.

In Table 2, the ratios among the anatomical features extracted are reported. Their percentage difference shows optimal overlapping of the main anatomical structures. The anatomical features were extracted from the underdrawing shown in the reflectogra- phies, allowing more accurate measurements (anatomical features are outlined in Fig. 7a and 7b).

Image processing applied to the IR images relative to the Angel faces are shown in Fig. $7(\mathrm{~d}-\mathrm{g})$; in particular, together with IR reflectography (Fig. 7d) the preparatory drawing extracted by the segmentation is shown in Fig. 7e. As a representative example, the contours of the face of the Angels and their rigid co-registration is reported in Fig. 7f. Fig. $7 \mathrm{~g}$ shows the co-registration among the contours of all faces (the Angels have been labelled with AR, BR, CR for the Angels in the right side and with AL, BL, CL for Angels at the left). A minimum rotation angle of $0.9^{\circ}$ and a maximum rotation angle of $5.8^{\circ}$ were obtained, showing very similar spatial orientation among all Angels. Furthermore, it is very interesting to observe that the SSI values are very similar to each other and that span from 0.874 (AL vs. BL) to 0.906 (BR vs. CR), values very near to 1, proving high similarity among the contours of the Angels. These results suggest the use of models in the Gable, and could be of fundamental importance for comparing the Giotto's Gable with the Baroncelli Polyptych by using the same methodology since a large number of apparently similar figures is depicted in the overall Polyptych.

\section{Conclusions}

Starting point of this research was the challenge to analyse a masterpiece in exhibition, without moving the panel and exploiting only the few hours of the museum closing time. To reach our aim we chose portable, fast and non-invasive synergic techniques, such 

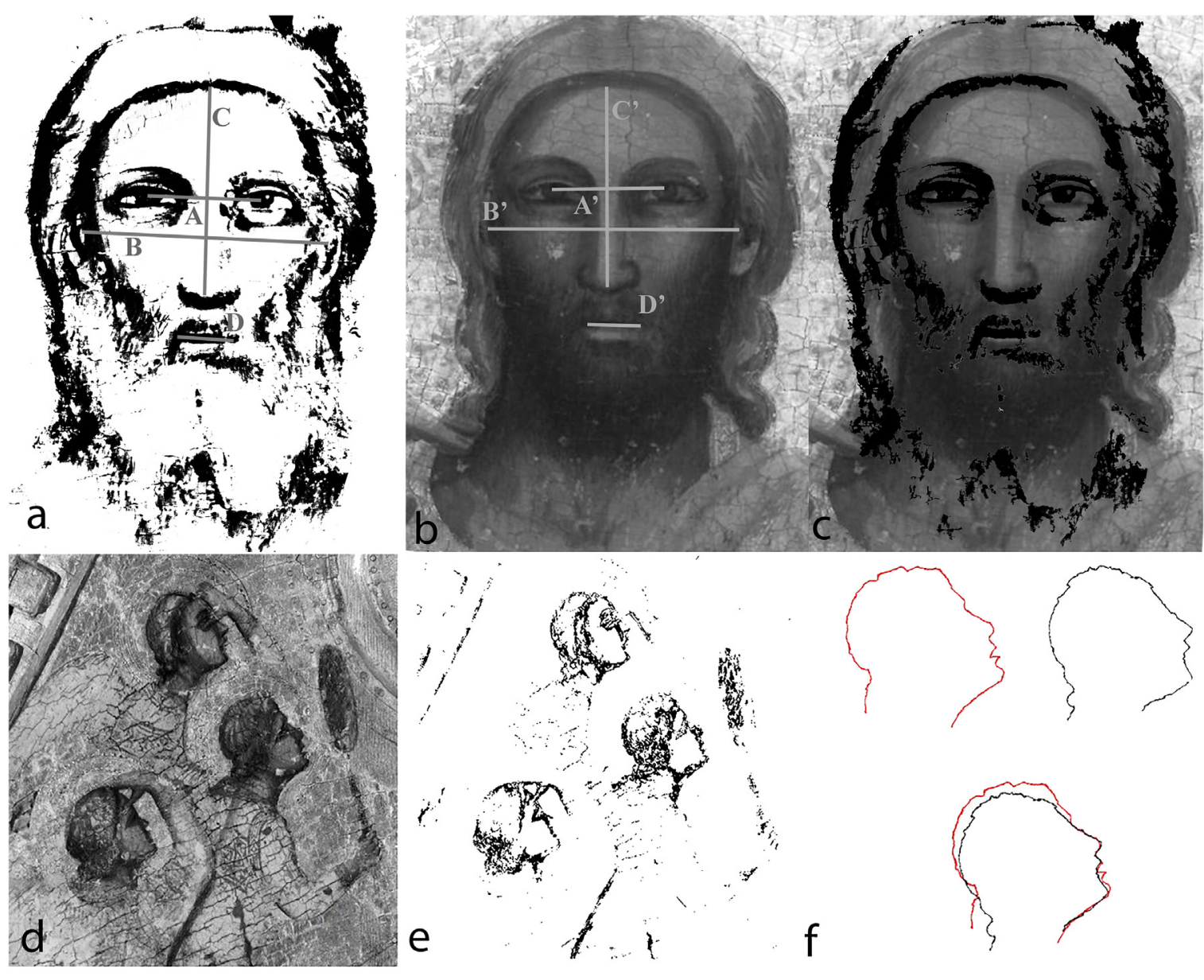

AR vs. ARI SSIM $=1.000 \quad$ AL vs. ALI SSIM $=1.000$

BR vs. BR I SSIIM $=1.000$

BL vs. BL I SSIM $=1.000$

CR vs. CR I SSIM $=1.000$

$f$

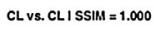

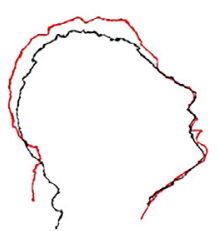

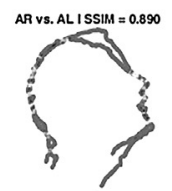

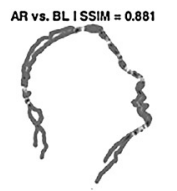<smiles>CC(C)CCCCCCC(C)C</smiles><smiles>C/C=C\C=C/[13CH]/C=C\C</smiles>

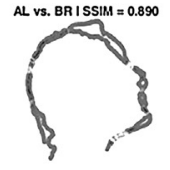

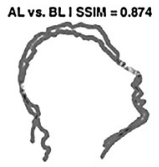

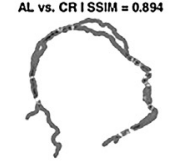

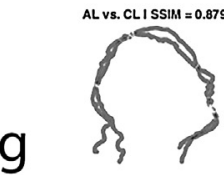

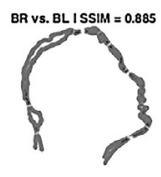

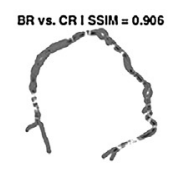

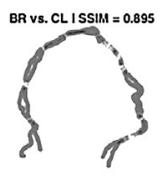

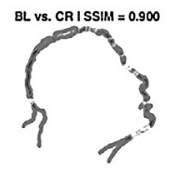

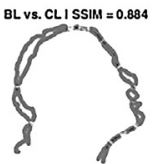

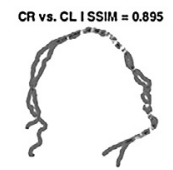

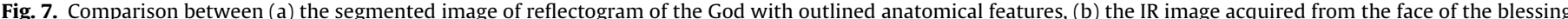

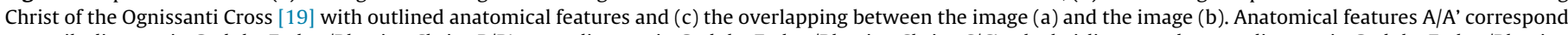

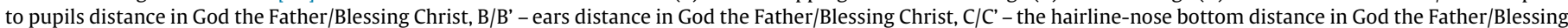

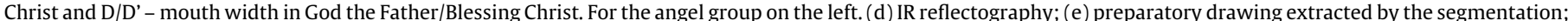
(f) contours of the face of the angels and their rigid co-registration; (g) co-registration among the contours of all Angels faces.

as IR imaging, IR false colour, MA-XRF scanning and FORS joined to $\mathrm{XRF}$ single point investigations. In addition, we developed fast and automatic data handling to get valuable results within the opening months of the exhibition, allowing the spectator to get advantages from our research. This allowed a complete characterization of the pigment used. The identified original palette includes the classical mediaeval pigments (vermillion, ochre, natural ultramarine blue...) mixed and applied in various layers. Challenging has been the reconstruction of the stratigraphic sequence of the detected materials based on different penetration depths of the applied techniques and the co-occurrence and correlation of elements in the XRF mapping. We argued that the stratigraphy corresponds to a vermilion-lead white layer superimposed to a gypsum-verdaccio one as in the Croce of Santa Maria Novella. 
Restoration areas were clearly identified, casting light on the conservative history of the Gable, unknown after the separation from the polyptych at the end of the XV century until the modern donation to S. Diego Museum. The imaging data support the hypothesis of a detailed underdrawing, including a drawing characterized by wider brush strokes.

The cross fertilisation with an image processing typical of biomedical science has been very successfully applied for the first time. Indeed the quantitative objective data obtained by analysing the IRR images allowed us to infer some art historical considerations. Moreover, we suggested the use of sketches for the face of "God the Father" and for the faces of Angels, thus looking inside Giotto's workshop from the XXI century.

\section{Acknowledgments}

The authors would like to especially thank Michael A. Brown, Associate Curator of European Art at the San Diego Museum of Art. The research has been supported by Fondazione Cariplo, grant No. 2015-2293.

\section{References}

[1] Giotto. L'Italia, S. Romano, P. Petraroia (Eds), Electa Mondadori, 2015

[2] L. Sebregondi, Giotto at Santa Croce, Polistampa, 2006.

[3] M. Gargano, N. Ludwig, G. Poldi, A new methodology for comparing IR reflectographic systems, Infrared Phys, Technol. 49 (2007) 249-253.

[4] L. Consolandi, D. Bertani, A prototype for high-resolution infrared reflectography of paintings, Infrared Phys. Technol. 49 (2007) 239-242.

[5] C. Daffara, E. Pampaloni, L. Pezzati, M. Barucci, R. Fontana, Scanning multispectral IR reflectography SMIRR: an advanced tool for art diagnostics, Acc. Chem. Res. 43 (2010) 847-856.

[6] T. Moon, M.R. Schilling, S. Thirkettle, A note on the use of false-colour infrared photography in conservation, Stud. Conserv. 37 (1992) 42-52.

[7] G. Verri, J. Dyer, J. Cupitt, Multispectral Imaging in Reflectance and Photoinduced Luminescence modes: a User Manual, European CHARISMA Project, Version 1.0, 2013.

[8] H.G.M. Edwards, P. Vandenabeele, Analytical archaeometry: selected topics, RSC Publishing, Cambridge; UK, 2012.

[9] S. Mosca, T. Frizzi, M. Pontone, R. Alberti, L. Bombelli, V. Capogrosso, A. Nevin, G. Valentini, D. Comelli, Identification of pigments in different layers of illuminated manuscripts by X-ray fluorescence mapping and Raman spectroscopy, Microchem. J. 124 (2016) 775-784.

[10] M. Alfeld, J. Vaz Pedroso, M. van Eikema Hommes, G. Van der Snickt, G. Tauber, J. Blaas, M. Haschke, K. Erler, J. Dik, K. Janssens, A mobile instrument for in situ scanning macro-XRF investigation of historical paintings, J. Anal. At. Spectrom. 28 (2013) 760-767.

[11] J. Dik, K. Janssens, G. van der Snickt, L. van der Loeff, K. Rickers, M. Cotte, Visualization of a lost painting by Vincent van Gogh using synchrotron radiation based X-ray fluorescence elemental mapping, Anal. Chem. 80 (2008) 6436-6442.
[12] L. Bonizzoni, S. Bruni, A. Galli, M. Gargano, V. Guglielmi, N. Ludwig, L. Lodi, M. Martini, Non-invasive in situ analytical techniques working in synergy: the application on graduals held in the Certosa di Pavia, Microchem. J. 126 (2016) $172-180$.

[13] L. Bonizzoni, S. Caglio, A. Galli, G. Poldi, A non-invasive method to detect stratigraphy, thicknesses and pigment concentration of pictorial multilayers based on EDXRF and Vis-RS: in situ applications, Appl. Phys. A. 92 (2008) 203-210.

[14] L. Bonizzoni, M. Gargano, N. Ludwig, M. Martini, A. Galli, Looking for common fingerprints in Leonardo's pupils using non-destructive pigment characterization, Applied Spectroscopy 71 (2017) 1915-1926.

[15] C.D. Cennini, The Craftsman's Handbook, Dover Pubns, New York, 1954.

[16] Giotto. Il restauro del Polittico di Badia. The restoration of the Badia Polypthic. Edited by di Angelo Tartuferi. Ed. Mandragora, 2012.

[17] Il restauro della Cappella degli Scrovegni. Indagini, progetto, risultati. Restoration of the Scrovegni Chapel. Surveys, project, results. Edited by Giuseppe Basile. Skira Editore, Milano, 2003.

[18] Il polittico di Giotto nella Pinacoteca Nazionale di Bologna, nuove letture. A cura di Diego Cauzzi e Claudio Seccaroni. Edifimi srl, Firenze, 2009.

[19] D. Bomford, J. Dunkerton, D. Gordon, A. Roy. Art in the Making. Italian Painting before 1400. National Gallery Publications Ltd, 1989.

[20] Giotto e compagni, sous la direction de Domique Thiébaut, Louvre éditions, Paris, 2013.

[21] Ricerche sul Polittico Stefaneschi. Giotto nella Pinacoteca Vaticana. A cura di Antonio Paolucci, Ulderico Santamaria, Vittoria Cimino, Edizioni Musei Vaticani, Electa, Città del vaticano, 2016.

[22] B.H. Berrie, M. Leona, R. McLaughlin, Unusual pigments found in a painting by Giotto (c. 1266-1337) reveal diversity of materials used by medieval artists, Herit. Sci. 4 (1) (2016), http://dx.doi.org/10.1186/s40494-016-0070-9.

[23] J. Shearman, A note on the early history of cartoons, Master Drawings 30 (1992) 5-8.

[24] L'officina di Giotto. Il restauro della Croce di Ognissanti. Marco Ciatti (Ed.), EDIFIR Firenze (2010), p 111

[25] A. Galli, M. Caccia, R. Alberti, L. Bonizzoni, N. Aresi, T. Frizzi, L. Bombelli, M. Gironda, M. Martini, Discovering the material palette of the artist: a p-XRF stratigraphic study of the Giotto panel "God the Father with Angels", X-Ray Spectrom. 46 (2017) 435-441.

[26] G. Marco, N. Ludwig, D. Pandini, Use of optical fibre in spectrometry and colorimetry with remote probes, JAIC J. Int. Colour Assoc. 8 (2012) 36-43.

[27] M. Gargano, F. Cavaliere, D. Viganò, A. Galli, N. Ludwig, New spherical scanning system for infrared reflectography of paintings, Infrared Phys. Technol. 81 (2017) 128-136.

[28] L'officina di Giotto. Il restauro della Croce di Ognissanti, Marco Ciatti (Ed.), EDIFIR Firenze (2010), p. 111

[29] W. Zhou, A.C. Bovik, H.R. Sheikh, E.P. Simoncelli, Image quality assessment: from error visibility to structural similarity, EEE Trans. Image Process. 13 (2004) 600-612.

[30] Gál, M. Čeppan, M. Reháková, V. Dvonka, J. Tarajčáková, J. Hanus, Chemometric tool for identification of iron-gall inks by use of visible-near infrared fibre optic reflection spectroscopy, Anal. Bioanal. Chem. 405 (2013) 9085-9091.

[31] M. Ciatti, M. Seidel: Giotto: The Crucifix in Santa Maria Novella Paperback. Deutscher Kunstverlag 2005.

[32] C.H. Li, P.K.S. Tam, An iterative algorithm for minimum cross entropy thresholding, Pattern Recognit. Lett. 18 (8) (1998) 771-776.

[33] Rasband, W.S., ImageJ, U. S. National Institutes of Health, Bethesda, Maryland, USA, https://imagej.nih.gov/ij/, 1997-2016.

[34] S. Kullback, Information Theory and Statistics, Wiley, New York, 1959. 